\title{
Facilitating Rapport through Real Patient Encounters in Health Care Professional Education
}

\author{
Linda Ross BParamedStud
}

Affiliations:

Department of Community Emergency Health \& Paramedic Practice, Monash University, Melbourne, Victoria, Australia

\begin{abstract}
Background

Establishing rapport is central to any health care professional-patient encounter. Developing a positive relationship with a patient enables the health care practitioner to elicit pertinent information and make informed clinical decisions about their treatment. This consequently leads to greater patient adherence, satisfaction and ultimately outcomes. As interpersonal communication and building patient rapport is integral to patient care it is imperative that the teaching of these skills be included in undergraduate and continuing health care professional education. The objective of this narrative review was to analyse the literature pertaining to health care professionals learning and developing interpersonal communication and rapport building skills through encounters with 'real patients'.
\end{abstract}

\section{Methods}

In April 2013 a search was conducted using the following electronic databases; MEDLINE, PsychINFO, CINAHL and ERIC. The search was limited to articles from peer-reviewed journals, conference papers and abstracts published between $1998-2013$ and written in English. Articles identified were assessed against the inclusion/exclusion criteria.

\section{Results}

An initial search located 6549 articles. Following the application of inclusion and exclusion criteria seven articles were included in this review. A synthesis and subsequent examination of the extracted data revealed positive results in regard to incorporating 'real patients' into interpersonal communication skills and practitioner-patient relationship teaching and learning. Some studies measured actual improvement in behaviour and skills whilst others offered self-reported data on participant perceptions of their skills

\section{Conclusion}

Training interventions involving 'real patients' that are designed to foster interpersonal communication, interviewing skills, practitioner-patient relationships and rapport building are achievable and beneficial for student and practicing health care professionals. Any conclusions drawn from this review however must remain preliminary until such time as more high-level research becomes available.

\section{Keywords}

Rapport, undergraduate students, interpersonal communication, real patients, healthcare

Corresponding Author: Linda Ross, linda.ross@monash.edu

\section{INTRODUCTION}

Establishing rapport is central to any health professional-patient encounter (1). O'Toole defines rapport as the development of a therapeutic relationship based on mutual understanding (respect, empathy and trust)(2).

Developing a positive relationship with a patient enables the health practitioner to elicit pertinent information and make informed clinical decisions about their treatment and ongoing care (3).

However rapport is more than that. It promotes communication, collaboration, and a shared understanding of the patient's perspective (4). It 
also requires much more than good intentions and is developed by the words and actions of the individuals involved (5). Literature in this area describes the importance of establishing rapport early in the patient encounter (1). It is also important to remembered that rapport is dynamic and threads through the entire course of the patient encounter (6). This narrative literature review will be conducted prior to further research to determine what is already known.

The most important reason for health professionals to establish rapport with patients is the positive impact this has on patient outcomes $(7,8)$. A positive trusting relationship between a health care practitioner and patient facilitates the garnering of information vital to the establishment of a diagnosis and correct treatment options (1, 5). In addition, a patient in a collaborative relationship with a health care practitioner they trust and respect is more likely to adhere to their treatment (9). Key studies in this area have confirmed the link between the establishment of this positive relationship and patient outcomes(10, 11). Furthermore, patients who have experienced positive rapport with their health practitioners report better levels of satisfaction with their treatment and are less likely to make a complaint or file malpractice suits (12).

Highly attuned interpersonal communication skills are fundamental in developing patient rapport (13), but should not be used interchangeably with rapport. Interpersonal communication is multidimensional and includes both verbal and non-verbal communication. Duffy, Gordon, Whelan, Cole-Kelly \& Frankel described interpersonal communication skills as "the effect communication has on another person" and find that "interpersonal skills build on basic communication skills, which alone are insufficient to create and sustain a therapeutic relationship"(14). Bakic-Miric \& Bakic suggest other factors conveyed through interpersonal communication, such as confidence, empathy, compassion, frankness, respect and thoroughness, are paramount to the success of rapport building(15). Therefore interpersonal communication skills are fundamentally linked to the process of establishing rapport. The relationship between interpersonal communication, rapport and patient outcomes is outlined in Figure 1.

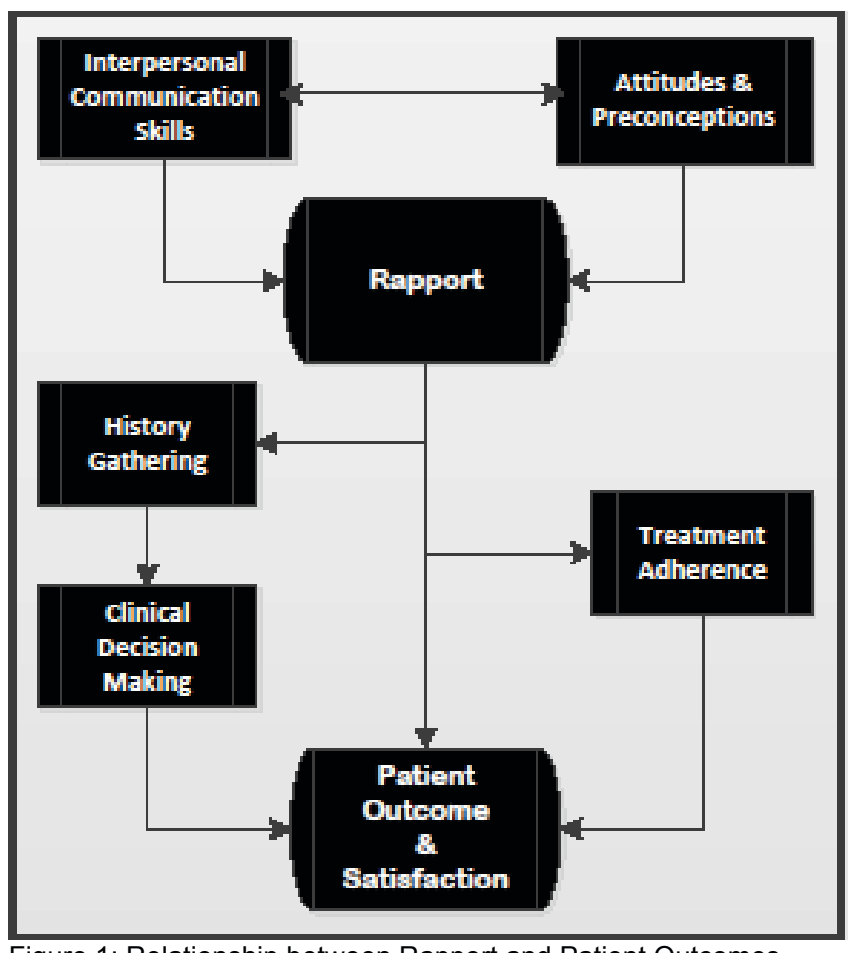

Figure 1: Relationship between Rapport and Patient Outcomes

With communication and the skill of building patient rapport integral to patient care and outcomes it is vital that the teaching of these skills be included in undergraduate health care professional education. Many institutions attempt this in the traditional didactic fashion, but this is notoriously complex and difficult $(7,12,16)$. Following a review of communication teaching and learning in medicine, Aspegren concluded that "instructional methods should not be used in the teaching of communication skills, since they are ineffective in comparison with experiential methods"(17). Instructional methods are therefore often coupled with practical applications including role plays with other students or standardised patients (actors playing the part of a patient) (13, 18). Often these teaching practices will include feedback from peers, educators, and/or the patients themselves. Some programs also integrate video-taped interactions to aid the discussion and feedback process. Another means for students to practise and develop these skills is in the field through clinical placement. Unfortunately opportunities to hone communication skills and personally connect with patients in the field are often overridden by the expectation to solicit information and make clinical decisions in a timely fashion(7). Another method for developing these skills, which is employed by many educators, is using encounters with 'real patients' with the explicit purpose of practicing interpersonal communication. There are however, many inconsistences in the literature surrounding the terminology used to describe patient involvement in health care professional education. Other terms frequently used include consumer, client, customer and service user (19). For the 
purpose of this review 'real patient' will be defined as "both people with health problems, whether or not they are currently receiving care and healthy people" (19). It does not include the use of standardised patients who are acting as 'real patients'; however several studies do refer to 'real patients' by this term (20).

Early contact with patients during undergraduate training is said to be integral to the development of communication skills which cannot be learnt through instruction (21). Direct contact with patients not only plays a crucial role in the development of communication skills but motivates students by promoting relevance and providing context (22). Interacting with 'real patients' allows students to form authentic emotional connections and express true empathetic responses as opposed to the often feigned, artificial interactions experienced with actors (9). In the words of John Hopkins Hospital's founding professor, William Osler, "it is a safe rule to have no teaching without a patient for a text, and the best teaching is taught by the patient himself"(23).

The objective of this narrative review is to analyse the literature pertaining to learning and developing interpersonal communication and rapport building skills in health care professionals, through encounters with 'real patients'. Results will be used to indicate what further research is required to fill existing gaps and add to the body of evidence supporting the use of 'real patients' in health care professional education.

\section{METHODS}

\section{Search Strategy}

In April 2013 a search was conducted using the following electronic databases; MEDLINE, PsychINFO, CINAHL and ERIC. The search was limited to articles from peer-reviewed journals, conference papers and abstracts published between 1998 -2013 and written in English. The Population-Intervention-Comparison-Outcome (PICO) model was used to formulate search terms (24). The population search included health personnel (MeSh) or 'health care professional*' or 'medical practitioner" and specific acute care health professions. The intervention terms included education (MeSh), 'teaching method*' or 'training' or 'experiential learning'. The outcome search contained 'interpersonal relations' (MeSh) or 'patient centered-care' or 'professional-patient relationship*' or rapport. These searches were then combined with 'and'. The full list of search terms used is available in Table 1. Further searching of Google Scholar, grey literature and secondary references was conducted to locate any additional relevant sources.

\section{Inclusion \& Exclusion Criteria}

A full text review was conducted of potentially relevant articles. These were assessed against the inclusion/exclusion criteria which included: only articles relating to the population; health personnel involved in acute health care, such as doctors, nurses and paramedics. These professions were chosen due to the similarities between patient encounters they experience in acute health care settings, such as in the field or emergency departments. These encounters are often in emergency situations where time is of the essence and communication takes on a more pressured feel. More specialist health care professions, such as physiotherapists, speech pathologists, podiatrist, and optometrists, with more time to communicate and establish rapport, were excluded. Those articles referring to interventions relating to education, training and teaching methods involving 'real patients' were also included, whilst articles pertaining to assessment of skills were excluded. Finally only articles concerned with patient relationships, interpersonal communication or rapport building skills were included. Articles relating to clinical skills or information gathering rather than relationship building were excluded.

\begin{tabular}{|c|c|}
\hline Dimension & Search Terms \\
\hline \multirow[t]{2}{*}{ Population } & $\begin{array}{l}\text { health personnel (MeSh) or health care professional* or medical practitioner** or health care } \\
\text { personnel or nurs* or paramedic* or medic* or ambulance or emergency medical service* or } \\
\text { emergency medical tech* or emt or ems or intern* or general pract }{ }^{*}\end{array}$ \\
\hline & AND \\
\hline \multirow[t]{2}{*}{ Intervention } & $\begin{array}{l}\text { education (MeSh) or teaching method }{ }^{*} \text { or experiential learning or practise or experience or } \\
\text { exposure or engagement or immersion or interaction or training }\end{array}$ \\
\hline & AND \\
\hline Outcome & $\begin{array}{l}\text { interpersonal relations (MeSh) or patient centered-care (MeSh) or professional-patient } \\
\text { relationship* or rapport or therapeutic alliance or therapeutic relationship or therapeutic rapport }\end{array}$ \\
\hline
\end{tabular}

Table 1 Search Terms

\section{RESULTS}

A total of 6549 articles were identified from the initial search. Following the removal of duplicates and a title and/or abstract review 58 suitable articles remained. After screening the full text a further 51 were excluded based on the inclusion/exclusion criteria. A total of seven articles fulfilling the inclusion criteria remained for analysis in this review (Figure 2).

Data from selected articles was extracted and synthesized for further analysis. A summary of these data are presented in Table 2. 


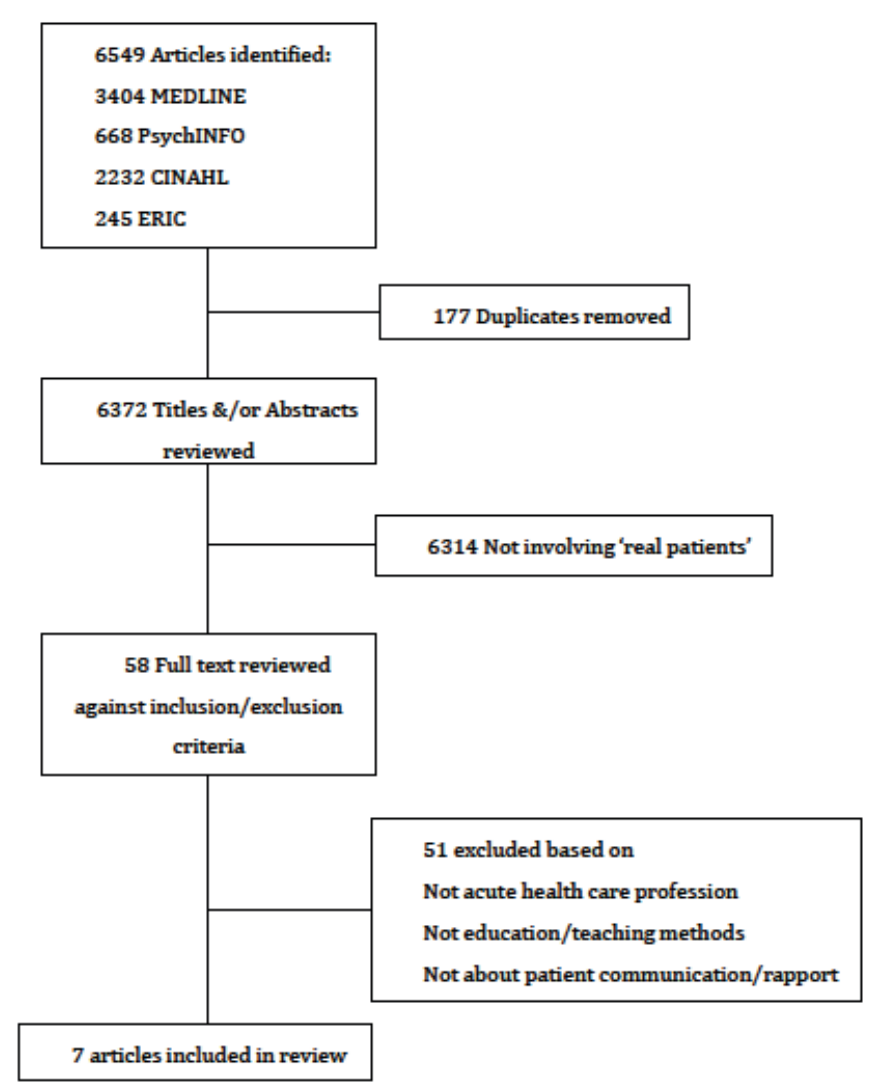

Figure 2: Search Strategy

\section{Quality Assessment}

The Best Evidence Medical Education (BEME) tool developed by Buckley et al. was used to assess the quality of each study (Table 3)(25). The BEME tool consists of eleven quality indicators related to the appropriateness of the study design, conduct of the research, results analysis and conclusions. The implementation of this tool results in a quality rating of either 'higher' (studies which met seven or more of the indicators) or 'lower' (studies which met less than seven).

All of the identified studies included in this literature review had clearly defined research questions with the exception of Scavenius et al. (26). In this paper the research objectives were expressed very differently at various points throughout the paper and remained ambiguous to the reader. Given the lack of clarity surrounding the research objective it was difficult to assess the results, discussion and conclusion. In addition, the results were unclear and not supported by more than one source of data. A culmination of inadequate clarity about the research purpose and deficient results led to this study being awarded a 'lower' quality rating.

The Norgaard et al. study utilized the same study design and data collection tools for a wide range of subjects, including clinical staff with administrative staff who have very differing communication requirements and goals (27). However the authors provided a thorough analysis, and reported the results of individual groups, allowing for the examination of individual professions. This coupled with other positive aspects such as clearly defined research questions and methods resulted in the attainment of a 'higher' quality rating.

Four of the five studies employing quantitative research methods used previously validated questionnaires to gather data. Clever et al., Norgaard et al. and Turan et al. adapted or added to tools to make them more specific to their purposes whilst Hook \& Pfeiffer used an unchanged tool $(8,9,13,27)$. Norfolk et al. on the other hand designed their own questionnaire which achieved a modest Cronbach's alpha coefficient reliability value of $0.66(4)$.

Hook \& Pfeiffer discussed confounding variables in their limitations and conceded that all the subjects had differing and unique experiences when interviewing individual patients (8). This was the case with each study as participants were interacting with real people and therefore each interaction had to be distinctive in some way. No other authors made mention of this.

Meili et al., Scavenius et al. and Turan et al. used thematic coding successfully to analyse qualitative 
data $(13,26,28)$. Norfolk et al. collected qualitative data but made no mention of its analysis in the reporting of results(4). The quantitative data analysis in Clever et al., Hook \& Pfeiffer, Norgaard et al. and Turan et al. was similarly thorough and based on sound scientific principles $(8,9,13,27)$. Norfolk et al. again reported results with no explanation of the analysis process utilised (4). Only the mixed methods studies; Norfolk et al. and Turan et al. supported their results with data from more than one source $(4,13)$. Only two papers; Clever et al. and Meili et al. discussed ethical issues whilst the others either did not obtain ethics approval or omitted this element from their published work (9, 28). With the exception of Norfolk et al. and Scavenius et al., all the studies came to conclusions which were supported by their results $(4,26)$.

Seven of the eight papers achieved a BEME quality rating of 'higher'. The Scavenius et al. study was awarded a 'lower' grading and therefore the results will not be considered in subsequent discussions (26). The BEME ratings received by each paper are documented in Table 2.

\section{Reported Results}

Five of the studies included for analysis involved medical students undertaking undergraduate studies. Three of these utilised first year students as their population $(9,26,28)$, whilst the other two involved students from first through to third and fourth years $(8,13)$. The remaining two studies made use of postgraduate professionals. The first included general practice trainees (4), whilst the second study looked at a broader population, including health care professionals from an orthopaedic surgery department (27). The population in this instance consisted of doctors, nurses, nursing assistants and other staff members. Seventy percent of those participating in this study were medical or nurse graduates.

\section{All of the seven selected studies discussed} curriculum and pedagogy designed to facilitate the acquisition of interpersonal, interviewing, communication and rapport building skills. Most employed traditional didactic methods in combination with an experiential practice involving 'real patients'. The Clever et al. study engaged students in medical interviews with both volunteer outpatients and simulated patients (9). Similarly Hook \& Pfeiffer, and Scavenius et al. introduced their medical students to clinical experience with 'real patients', with a focus on relationship building, rather than data gathering in the early years of training $(8,26)$. Meili et al. also had students interacting with 'real patients' but in different contexts; in home and community settings as opposed to hospital or general practice settings (28).

Several of the studies utilised video-taped encounters to assist in providing feedback post interactions; Norgaard et al. and Turan et al. (13, 27). Meili et al. and Norfolk et al. employed selfreflection as a feedback mechanism, whilst Clever et al. and Hook \& Pfeiffer had immediate feedback delivered by patients or faculty staff and peers $(4$, $8,9,28)$.

In relation to methodology, only three of the studies employed quantitative research methods; Clever et al., Hook \& Pfeifer and Norgaard et al $(8,9,27)$. The Clever et al. (9) study utilized a modified version of the Maastricht Assessment of Simulated Patients (MASP) (18). Additional items pertinent to the learning environment and simulated patients were identified in focus groups, validated through cognitive interviewing and added to the tool. Both student participants and faculty staff completed the questionnaire comprising of ten and eight items respectively, using a four-point Likert scale. Similarly the Hook \& Pfeifer study used a previously validated assessment tool, the Arizona Clinical Interviewing Rating Scale (ACIR), consisting of 20 items with a five-point Likert scale (8). In this instance however, only the staff rated the students' performance following viewing of a videotaped interview with a patient. Student results were also measured longitudinally over a four year duration. The Norgaard et al. (27) study likewise modified a previously validated questionnaire by Parle, Maguire \& Heaven, which consisted of 19 questions and a ten-point scale (29). This questionnaire was based on self-efficacy in communicating with patients and was completed by student participants.

Two studies employed qualitative research methods; Meili et al. and Scavenius et al. $(26,28)$. The Meili et al. team developed a nine item openended questionnaire specifically for their project (28). The questions were designed to elicit participants' reflections on their experiences interacting with 'real patients'. The Scavenius et al. study evaluated reflective case presentations by students following real patient encounters to elicit their data (26).

The Norfolk et al. and Turan et al. studies both employed mixed research methods $(4,13)$. The Turan et al. study collected qualitative data from focus group meetings and interviews, and quantitative data by using a Standardised Patient Encounter (SPE) evaluation form designed by the program coordinators to assess communication skills (13). The SPE evaluations were completed by the authors following viewing the video-taped encounters. Norfolk et al. utilised a 12 item questionnaire mixed with five-point Likert scale 


\begin{tabular}{|c|c|c|c|c|c|c|}
\hline $\begin{array}{l}\text { Study } \\
\text { Author } \\
\text { \& Year }\end{array}$ & $\begin{array}{c}\text { Country of } \\
\text { Origin }\end{array}$ & $\begin{array}{l}\text { Research } \\
\text { Methods }\end{array}$ & Population & Study Summary & $\begin{array}{l}\text { BEME } \\
\text { Quality } \\
\text { Grading }\end{array}$ & Outcomes \\
\hline $\begin{array}{l}\text { Clever et } \\
\text { al., } 2011\end{array}$ & USA & Quantitative & $\begin{array}{l}121 \text { first year } \\
\text { medical } \\
\text { students }\end{array}$ & $\begin{array}{l}\text { Students } \\
\text { conducted } \\
\text { interviews with } \\
\text { simulated patients } \\
\text { and volunteer out- } \\
\text { patients. } \\
\text { Perceptions were } \\
\text { rated post each } \\
\text { interview type and } \\
\text { then compared. }\end{array}$ & Higher & $\begin{array}{l}\text { Students rated } \\
\text { volunteer patients } \\
\text { higher in all domains } \\
\text { including } \\
\text { relationship building } \\
\text { and communication. }\end{array}$ \\
\hline $\begin{array}{l}\text { Hook \& } \\
\text { Pfeiffer, } \\
2007\end{array}$ & USA & Quantitative & $\begin{array}{l}202 \text { pre- } \\
\text { clinical } \\
\text { medical } \\
\text { students } \\
\text { (years } 1-4 \text { of } \\
\text { medical } \\
\text { school) }\end{array}$ & $\begin{array}{l}\text { Compared student } \\
\text { interviewing skills } \\
\text { post new } \\
\text { curriculum. New } \\
\text { curriculum } \\
\text { included } \\
\text { community setting } \\
\text { practising with real } \\
\text { patients. }\end{array}$ & Higher & $\begin{array}{l}\text { Showed an } \\
\text { improvement in } \\
\text { interviewing skills } \\
\text { and less of a decline } \\
\text { in results over time. }\end{array}$ \\
\hline $\begin{array}{l}\text { Meili et } \\
\text { al., } 2011\end{array}$ & Canada & Qualitative & $\begin{array}{l}14 \text { first year } \\
\text { medical } \\
\text { students }\end{array}$ & $\begin{array}{l}\text { Service learning } \\
\text { project which had } \\
\text { objectives } \\
\text { including } \\
\text { 'improving } \\
\text { communication } \\
\text { skills'. }\end{array}$ & Higher & $\begin{array}{l}\text { Gained insight into } \\
\text { the importance of } \\
\text { forming relationships } \\
\text { with patients and } \\
\text { improved language } \\
\text { and communication } \\
\text { skills. }\end{array}$ \\
\hline $\begin{array}{l}\text { Norfolk et } \\
\text { al., } 2009\end{array}$ & UK & $\begin{array}{l}\text { Quasi- } \\
\text { experimental/ } \\
\text { mixed } \\
\text { methods }\end{array}$ & $\begin{array}{l}37 \mathrm{GP} \\
\text { trainees }\end{array}$ & $\begin{array}{l}\text { GP trainees } \\
\text { participated in } \\
\text { training then kept a } \\
\text { reflective diary of } \\
\text { their patient } \\
\text { interactions, } \\
\text { followed by a } \\
\text { review phase. }\end{array}$ & Higher & $\begin{array}{l}\text { Participants showed } \\
\text { increase in attitudes, } \\
\text { confidence and } \\
\text { motivation to } \\
\text { develop rapport. }\end{array}$ \\
\hline $\begin{array}{l}\text { Norgaard } \\
\text { et al, } \\
2012\end{array}$ & Denmark & Quantitative & $\begin{array}{l}181 \text { health } \\
\text { care } \\
\text { professionals }\end{array}$ & $\begin{array}{l}\text { Communication } \\
\text { skills training } \\
\text { followed by } 6 \\
\text { weeks of practice } \\
\text { with real patients. }\end{array}$ & Higher & $\begin{array}{l}\text { All participants had } \\
\text { improved self- } \\
\text { efficacy scores in } \\
\text { communication } \\
\text { skills. }\end{array}$ \\
\hline $\begin{array}{l}\text { Scavenius } \\
\text { et al, } \\
2006\end{array}$ & $\begin{array}{l}\text { The } \\
\text { Netherlands }\end{array}$ & Qualitative & $\begin{array}{l}503 \text { first year } \\
\text { medical } \\
\text { students }\end{array}$ & $\begin{array}{l}\text { Each student spent } \\
4 \text { weeks working } \\
\text { with real patients, } \\
\text { and then produced } \\
\text { a case } \\
\text { presentation. }\end{array}$ & Lower & $\begin{array}{l}\text { Analysis showed a } \\
\text { concern for } \\
\text { developing patient } \\
\text { relationships and } \\
\text { patient-centred care. }\end{array}$ \\
\hline $\begin{array}{l}\text { Turan et } \\
\text { al, } 2009\end{array}$ & Turkey & $\begin{array}{l}\text { Descriptive, } \\
\text { mixed } \\
\text { methods }\end{array}$ & $\begin{array}{l}216 \text { medical } \\
\text { students } \\
\text { (years 1-3) }\end{array}$ & $\begin{array}{l}\text { Students } \\
\text { participated in a } \\
\text { structure } \\
\text { communication } \\
\text { skills training } \\
\text { program and } \\
\text { interacted with real } \\
\text { patients in the } \\
\text { field. }\end{array}$ & Higher & $\begin{array}{l}\text { Achieved better } \\
\text { communication skills } \\
\text { when trained in } \\
\text { laboratories and real } \\
\text { settings. }\end{array}$ \\
\hline
\end{tabular}


Quality Indicator

Research question

Study subjects

Data collection methods

Completeness of data

Control for confounding

Analysis of results

Conclusions

Reproducibility

Prospective

Ethical issues

Triangulation
Detail

Is the research question(s) or hypothesis clearly stated?

Is the subject group appropriate for the study being carried out (number, characteristics, selection, and homogeneity)?

Are the methods used (qualitative or quantitative) reliable and valid for the research question and context?

Have subjects dropped out? Is the attrition rate less than $50 \%$ ?

For questionnaire based studies, is the response rate? Acceptable ( $60 \%$ or above)?

Have multiple factors/variables been removed or accounted for where possible?

Are the statistical or other methods of results analysis used appropriate?

Is it clear that the data justify the conclusions drawn?

Could the study be repeated by other researchers?

Does the study look forwards in time (prospective) rather than backwards (retrospective)?

Were all relevant ethical issues addressed?

Were results supported by data from more than one source?

Table 3 Best Evidence Medical Education (BEME) Quality Indicators (25) and open-ended questions (4). Rapport measures were also reported following expert analysis of taped interviews against a 22 point behavioural coding frame designed using a model of therapeutic rapport by Norfolk \& Patterson (30).

Clever et al. recruited 121 first year medical students to participate in two interviews with 'real patients'(9). Following their interview the students filled out the MASP questionnaire. Result analysis from the 237 questionnaires available indicated that students rated interactions with volunteer outpatients significantly higher than those with simulated patients. The statistical analysis showed improvements in several of the questionnaire items; 'feeling comfortable when interviewing the patient and learned a lot from this session' $(p=0.02)$; 'opportunity to develop a relationship with the patient and the patient appeared to withhold information unnecessarily' $(p=0.01)$; 'the patient was friendly to me and the interview met my training needs in developing communication skills' $(p<0.001)$. Whilst the students overwhelmingly favoured the encounters with volunteer outpatients over simulated patients, the analysis of the faculty perceptions reached no statistical significance. Despite this Clever et al. concluded that "students find true value in communication skills training with real patients"(9).

Hook and Pfeiffer assessed $(n=292)$ students in 1998 who participated in the 'old curriculum' and $(n=202)$ students in 2005 who were exposed to the new curriculum which utilised interaction with 'real patients'(8). The student's ability to relate to patients was assessed using the ACIR Scale. They reported that in the new curriculum which included 'real patient' interaction "students acquired interpersonal interviewing skills earlier and these skills declined less steeply than they had done in the prior curriculum" (8). They recorded statistically significant improvements in rapport in years one and two, interviewing skills in first and fourth year students and social history 
taking in years one, two and four (8). (These results were reported as $p \leq 0.05$ ).

Meili et al. analysed fourteen medical student's reflections of a service learning project and extracted the following themes: relationships, social determinants of health in real life, community development, interdisciplinarity, linking health and communities, and personal learning (28). Reflections in each of these categories indicated students gained language skills and improved their interpersonal communication skills. Students also felt it was important to gain real world experiences in their medical training (28).

Norfolk et al. gathered data from 37 GP trainees involved in a communication training with 'real patients' and 10 GP trainees not involved in the training (4). By comparing results from questionnaires completed and various intervals throughout the program they found that the training group demonstrated significant increases in attitude to rapport, confidence in developing rapport and motivation to develop rapport, in contrast to the control group which showed no significant change. Expert raters also reported significant positive change in all rapport-related behaviours after the training. Empathetic motivation, empathetic skills, communication skills and overall rapport all rated substantial higher (4).

In the Norgaard et al. study, 177 participants answered a questionnaire on self-efficacy in communication before (pre-test), 165 immediately after (post-test) and 150 six months after (followup) the training course involving contact with 'real patients'(27). The results following this communication skills training intervention showed an overall increase in self-efficacy $(p<0.001)$. The doctors participating only showed an improvement from pre-test to post-test, however their overall improvement from pre-test to follow up was not significant. All other staff; nurses, nursing assistants and secretarial staff had significant improvements in self-efficacy from pre-test to follow up. They conceded however that it is unknown whether these increases in self-efficacy scores led to actual changes in communication behaviour (27).

Turan et al. analysed pre and post site visitation surveys from 446 second and third year medical students (13). The results showed significant improvements $(p<0.01)$ in communication skills where students interacted with 'real patients'. Some students felt the site visits had a positive impact on their development of communication skills and motivated them to achieve further in this area. Others however commented negatively on the experience based on the lack of opportunities given to them by their supervising doctor (13).
All the studies contained within this review reported positive results following the incorporation of interpersonal communication skills training involving 'real patients'. Various methodological approaches and measuring techniques were employed but the common overarching themes emerging are consistent. Students and current practitioners alike relish the opportunity to interact and engage with 'real patients' and benefit from a deliberate focus on effective communication. The following discussion will synthesise and examine the key benefits to the inclusion of 'real patients' in health care professional education whilst also considering some of the drawbacks, limitations and associated issues.

\section{DISCUSSION}

The aim of this review was to determine the value of learning and developing interpersonal communication and rapport building skills in health care professionals through encounters with 'real patients'. Many studies examined the impact of 'real patients' in health care professional education however only a small number were identified that dealt specifically with interpersonal communication and rapport building skills. The resultant benefits of involving 'real patients' in communication skills training for health care personnel will be discussed below. Any conclusions drawn from this review however must remain preliminary until such time as more highlevel research becomes available. Nevertheless, a number of key themes emerged from the results which warrant further discussion.

\section{Experiential Learning with 'real patients'}

Experiential communication skills training can heighten student awareness of their own abilities, allow for self-reflection and increase motivation. Turan et al. and Norfolk et al. observed that practising communication with 'real patients' followed by self-reflection was a great motivator and fostered improvement and development in these skills $(4,13)$. Two studies, Clever et al. and Meili et al. reported results supporting the benefit of interactions with 'real patients' with respect to the patient-centred approach and relationship development $(9,28)$. Participants found interactions with 'real patients' to be more authentic and meaningful which resulted in them experiencing the development of a true emotional relationship rather than a feigned simulated relationship. Results illustrated a strong association between the value of the learning experience and the opportunity to develop a relationship with the patient (9). Meili et al also found that students were able to gain greater meaning from forming authentic relationships 
which had a positive impact on preconceived stereotypes and implications for future practice (28).

\section{Communication Confidence}

Another emerging theme was an overwhelming increase in confidence and comfort when engaging with patients after participating in training utilising 'real patients'. Students in the Norfolk et al. study self-reported a significant improvement in confidence (4) whilst students in the Clever et al. project reported feeling far more comfortable interviewing patients than they had done previously (9). The opportunity to gain confidence in communication skills and relationship building without the pressure of clinical decision making would appear to be an essential consideration. Hook and Pfeiffer were able to conclude from their longitudinal study that students benefited from early exposure to 'real patients' during their pre-clinical years (8). Whilst their results showed an eventual decline in these skills once the focus shifts to clinical decisionmaking the end result remained significantly higher than that of the earlier cohorts not exposed to 'real patients' early.

\section{Study Limitations}

A limiting factor in three studies was the use of self-reported perceptions of participants' interpersonal communication post the intervention $(4,9,28)$. Devoid of a direct measure of the acquisition of skills these results cannot reasonably be considered a predictor of actual behaviour. Perception of skill acquisition does not necessarily equate to actual skill acquisition. It must ideally be measured through observation.

An additional limitation related to the utilisation of real patients in communication training is the lack of continuity between encounters, not only from patient to patient, but also between encounters with the same patient (8). Training and scripting of patients; be they standardised or 'real patients', could be utilised in an effort to minimise this confounder and increase consistency between encounters. Unfortunately this strategy would only serve to jeopardise the value gained through authentic interactions with 'real patients'.

This review indicates that patient interaction in health care professional education has an important role to play for novice and practicing professionals alike. The value appears to lie in the authentic nature of the relationships formed with 'real patients'. These valuable experiential learning opportunities allow health care professionals to learn from and with patients in relevant contexts. The nature and extent of involvement can vary from on-off minimal interaction to long term partnerships with educators however careful planning and execution must occur to ensure ethical and safety considerations are met. Future exploration and research in this area will uncover the true value of 'real patient' encounters in health care professional education.

\section{Review Limitations}

The literature on 'real patient' involvement in health care professional education is difficult to locate through simple search strategies. Keywords used to index papers lack consistency and abstracts use a wide variety of descriptive terms, as mentioned previously. Adding to the complexity is the use of patients in varying capacities from once-off involvement to partnerships with educators, and the divergent objectives of their involvement which include clinical skills, community awareness and in the case of this review, interpersonal communication skills.

Another issue and limitation is the paucity of nonmedical literature. These views are echoed by Towle et al, who conducted a similar review into patient involvement in health care professional education (31). While their review focused on patient involvement in all areas of health care professional education, not specifically interpersonal communication, they also found the majority of research came from medicine with the remaining scattered amongst other health professions.

\section{CONCLUSION}

Training interventions involving 'real patients', that are designed to foster interpersonal communication, and rapport building are achievable and beneficial for student and practicing health care professionals. This review indicates that students benefit from the authentic nature of interactions and the experience of forming meaningful relationships with patients. They reported improved comfort, confidence, awareness, knowledge, motivation and value in the learning experience. Interventions with 'real patients' designed to enhance communication also appear to be best positioned early in education and training where these skills can be developed in isolation from clinical reasoning and decision making skills which in the novice detracts from the ability to build relationships.

\section{CONFLICT OF INTEREST}

The author declares she has no conflict of interest. 


\section{ACKNOWLEDGEMENTS}

I would like to thank Associate Professor Brett Williams for his assistance with the search strategy and manuscript review.

\section{REFERENCES}

1. Leach MJ. Rapport: a key to treatment success. Complement Ther Clin Pract. 2005;11(4):262-5.

2. O'Toole G. Communication: Core interpersonal skills for health professionals. Chatswood NSW: Churchill Livingstone; 2008.

3. Barnett PB. Rapport and the hospitalist. Am J Med. 2001;111(9):31-5.

4. Norfolk T, Birdi K, Walsh D. The role of empathy in establishing rapport in the consultation: a new model. Med Educ. 2007;41(7):690-7.

5. Rosenzwelg S. Emergency rapport. J Emerg Med. 1993;11(6):775-8.

6. Arnold EC, Boggs KU. Interpersonal Relationships: Professional Communication Skills For Nurses. Missouri USA: Saunders; 2010.

7. Egnew TR, Wilson HJ. Faculty and medical students' perceptions of teaching and learning about the doctor-patient relationship. Patient Educ Couns. 2010;79(2):199-206.

8. Hook KM, Pfeiffer CA. Impact of a new curriculum on medical students' interpersonal and interviewing skills. Med Educ. 2007;41(2):154-9.

9. Clever SL, Dudas RA, Solomon BS, Yeh HC, Levine D, Bertram A, et al. Medical student and faculty perceptions of volunteer outpatients versus simulated patients in communication skills training. Acad Med. 2011;86(11):1437-42.

10. Hojat M, Louis DZ, Markham FW, Wender R, Rabinowitz C, Gonnella JS. Physicians' empathy and clinical outcomes for diabetic patients. Acad Med. 2011;86(3):359-64.

11. Del Canale S, Louis DZ, Maio V, Wang X, Rossi G, Hojat M, et al. The relationship between physician empathy and disease complications: an empirical study of primary care physicians and their diabetic patients in parma, italy. Acad Med. 2012;87(9):1243-9.

12. Deveugele M, Derese A, De Maesschalck S, Willems S, Van Driel M, De Maeseneer J. Teaching communication skills to medical students, a challenge in the curriculum? Patient Educ Couns. 2005;58(3):265.

13. Turan S, Elcin M, Uner S, Odabasi O, Sayek I, Senemoglu N. The impact of clinical visits on communication skills training. Patient Educ Couns. 2009;77(1):42-7.
14. Duffy FD, Gordon GH, Whelan G, Cole-Kelly $\mathrm{K}$, Frankel R. Assessing competence in communication and interpersonal skills: the Kalamazoo II report. Acad Med. 2004;79(6):495-507.

15. Bakić-Mirić M, Bakić M. Successful doctorpatient communication and rapport building as the key skills of medical practice. Facta Univers. 2008;15(2):74-9.

16. Stephenson A, Higgs R, Sugarman J. Teaching professional development in medical schools. The Lancet. 2001;357(9259):867-70.

17. Aspegren K. BEME Guide No. 2: Teaching and learning communication skills in medicine-a review with quality grading of articles. Med Teach. 1999;21(6):563-70.

18. Wind LA, Van Dalen J, Muijtjens AM, Rethans JJ. Assessing simulated patients in an educational setting: the MaSP (Maastricht Assessment of Simulated Patients). Med Educ. 2004;38(1):39-44.

19. Spencer J, McKimm J. Patient Involvement in Medical Education. Understanding Medical Education: Evidence, Theory and Practice. Oxford UK: Wiley-Blackwell; 2010.

20. Jha V, Quinton ND, Bekker HL, Roberts TE. Strategies and interventions for the involvement of real patients in medical education: a systematic review. Med Educ. 2009;43(1):10-20.

21. Bokken L, Rethans J-J, Jöbsis Q, Duvivier R, Scherpbier A, van der Vleuten C.

Instructiveness of real patients and simulated patients in undergraduate medical education: a randomized experiment. Acad Med. 2010;85(1):148-54.

22. Spencer J, Blackmore D, Heard S, McCrorie P, McHaffie D, Scherpbier A, et al.

Patient - oriented learning: a review of the role of the patient in the education of medical students. Med Educ. 2000;34(10):851-7.

23. Osler W. The hospital as a college. Aequanimatus, and other addresses. London: HK Lewis; 1905.

24. Oxman AD, Cook DJ, Guyatt GH, Group EBMW. Users' guides to the medical literature. JAMA. 1994;272(17):1367-71.

25. Buckley S, Coleman J, Davison I, Khan KS, Zamora J, Malick S, et al. The educational effects of portfolios on undergraduate student learning: A Best Evidence Medical Education (BEME) systematic review. BEME Guide No. 11. Med Teach. 2009;31(4):282-98.

26. Scavenius M. Genesis of the professional-patient relationship in early practical experience: qualitative and quantitative study. Med Educ. 2006;40(10):1037-44. 
27. Norgaard B, Ammentorp J, Kyvik KO, Kofoed P-E. Communication Skills Training Increases Self-Efficacy of Health Care Professionals. J Contin Educ Health Prof. 2012;32(2):90-7. English.

28. Meili R, Fuller D, Lydiate J. Teaching social accountability by making the links: qualitative evaluation of student experiences in a service-learning project. Med Teach. 2011;33(8):659-66. English.

29. Parle M, Maguire P, Heaven C. The development of a training model to improve health professionals' skills, self-efficacy and outcome expectancies when communicating with cancer patients. Soc Sci Med. 1997;44(2):231-40.

30. Norfolk T, Patterson F. Developing the personal competencies of GP registrars: new training modules. London: City University; 2004.

31. Towle A, Bainbridge L, Godolphin W, Katz A, Kline C, Lown B, et al. Active patient involvement in the education of health professionals. Med Educ. 2010;44(1):64-74. 